\title{
Assessment of thermal environments: working conditions in the portuguese glass industry
}

\author{
A. Virgílio M. OLIVEIRA ${ }^{1,2 *}$, Adélio R. GASPAR ${ }^{1}$, António M. RAIMUNDO ${ }^{1}$ and \\ Divo A. QUINTELA ${ }^{1}$
}

\author{
${ }^{1}$ ADAI, LAETA, Department of Mechanical Engineering, University of Coimbra, Portugal \\ ${ }^{2}$ Coimbra Institute of Engineering, Polytechnic Institute of Coimbra, Department of Mechanical Engineering, Portugal \\ Received March 27, 2017 and accepted August 8, 2017 \\ Published online in J-STAGE August 19, 2017
}

\begin{abstract}
The objective of the present contribution is to assess the exposure to hot thermal environments in the Portuguese glass industry. For this purpose a field survey was carried out and the measurements took place in industrial units - five industries and nineteen workplaces were considered-so all the results are based on real working conditions. In order to assess the level of heat exposure the Wet Bulb Globe Temperature (WBGT) index and the Predicted Heat Strain (PHS) model, defined in ISO Standards 7243 (1989) and 7933 (2004), respectively, were used. According to the WBGT index, the results show that almost $80 \%$ of the workplaces under analysis are prone to heat stress conditions. If the PHS model is considered, the results highlight that the predicted and the maximum sweat rates present equal values in about $40 \%$ of the workplaces. In addition, in almost $25 \%$ of the workplaces the estimated rectal temperature was higher than $38^{\circ} \mathrm{C}$, just for an exposure period of one hour. Thus, the present study brings to light the characteristics of the glass industry in terms of the occupational exposure to hot environments and places this activity sector as one of the most difficult to deal with.
\end{abstract}

Key words: Health and safety, Heat stress, WBGT index, PHS model, Industrial units, Glass industry

\section{Introduction}

Science has been proving over the years that extreme thermal environments do have a negative impact on human comfort. Today there is a generalized consensus about this fact and no one discharges this reality. The same agreement regards the increasing pressure put on workers concerning productivity and efficiency. In industrial contexts, beyond the intrinsic characteristics of the activity, these burdens play a role in workers' productivity, overall well-being and health. The present contribution addresses this matter in what concerns the exposure of workers to adverse thermal environments, namely in the Portuguese glass industry. For

*To whom correspondence should be addressed.

E-mail: avfmo@isec.pt

(C)2018 National Institute of Occupational Safety and Health such hot thermal environments the scientific community has at his disposal a great number of heat stress indexes and models that can be used for its assessment. Epstein and Moran ${ }^{1)}$ have gathered a significant amount of data and present a list that starts in 1905 and ends in 2005. For the present study we have selected the Wet Bulb Globe Temperature (WBGT) index ${ }^{2}$ and the Predicted Heat Strain (PHS) model ${ }^{3)}$.

The Wet Bulb Globe Temperature (WBGT) index, defined $i^{2)}$, despite being probably the most widely method used to evaluate hot thermal environments, particularly in industrial units, is only an empirical indicator of heat stress conditions. On the contrary, the Predicted Heat Strain (PHS), defined in $^{3)}$, is a detailed heat stress model, thus frequently applied whenever a detailed analysis of specific workplaces is foreseen ${ }^{4}$.

The WBGT, due to its simplicity, is often regarded as 
a screening method, thus commonly considered by users and by occupational and health professionals as a method that provides a "fast" diagnosis ${ }^{5,6)}$ despite an apparent unawareness of its limitations and measuring errors, which are often neglected and thus may lead to important misunderstandings of the results ${ }^{7-9}$ ). Therefore, today, the WBGT index is not the more suitable tool for the assessment of working conditions. Its details, history, applicability and assessment (namely, limitations, measurement errors and the use of non-standard instrumentation) can be found elsewhere ${ }^{2,5,7,8,10-12)}$.

The Predicted Heat Strain (PHS) model derived from a previous heat stress index, the "Required Sweat Rate $\left(S w_{\text {req }}\right)^{\text {"13) }}$, was developed by Malchaire et al. $(2001)^{14)}$ and later integrated as part of the revised standard ${ }^{3}$. It predicts human physiological responses, based on an evaluation of some core body parameters and their evolution over time, of a subject exposed to a hot environment. Namely, the PHS model predicts the person sweat rate $\left(S w_{p}, \mathrm{~W} \mathrm{~m}^{-2}\right)$, evaporative heat rate $\left(E_{p}, \mathrm{~W} \mathrm{~m}^{-2}\right)$, skin wettedness $\left(w_{p}\right.$, dimensionless), rectal temperature $\left(t_{r e},{ }^{\circ} \mathrm{C}\right)$ and cumulated water loss (SWTOTg, g), and calculates the maximum exposure time to protect $50 \%$ and $95 \%$ of worker's population $^{3,14,15)}$. With this model, it is also possible to evaluate the required values of the previous parameters (i.e. of $S w_{\text {req }}, E_{\text {req }}, w_{\text {req }}$, etc.) to maintain the human body within the limits of thermal equilibrium. Hence, the PHS model, despite some limitations, provides reliable assessments in most cases and this is the reason why it is standardized and suggested by ISO $15265^{4}$ for the assessment of the class of risk. Details of the PHS model applicability, calculation methodology, experimental validation and assessment (namely, limits of validity, limitations and statistical confidence) can be found elsewhere ${ }^{3,4,14-20)}$.

In addition, in studies regarding industrial environments, the ergonomic approach of the SOBANE strategy ${ }^{21)}$ has to be considered whenever safety and health of workers are foreseen. This special strategy currently in use for $15 \mathrm{yr}$ and validated in 14 fields, including the thermal environment ${ }^{22}$, is organized in four levels (Screening, Observation, Analysis and Expertise) and some of its principles were adopted by ISO $15265^{4)}$ which describes a strategy for assessing and interpreting the risk of physiological constraints, or of discomfort, while working in a given environment.

Hence, the study of hot thermal environments has deserved great attention and a large number of studies have been carried all over the world in the last yr. The evaluation of the thermal environment of two mecha- nized and two non-mechanized glass factories made by Abeysekera $^{23)}$ in Sri Lanka revealed situations where workers' heat stress conditions occurred near furnaces, but less acute in mechanical ones. Bhanarkar et al. ${ }^{24)}$ report working shifts of $8 \mathrm{~h}$ with continuous exposures to high temperatures in different areas of glass manufacturing units in India. Their WBGT results show heat stress exposures greater than the recommended levels specified by the American Conference of Governmental Industrial Hygienists (ACGIH). Malchaire ${ }^{15)}$ addressed the occupational heat stress with the Predicted Heat Strain model and Parsons ${ }^{5)}$ analysed the global application of ${ }^{2)}$ based on the WBGT index. In the field study of Pourmahabadian et $a l .{ }^{25)}$ heat exposure measurements were made and the heat stress among workers in a glass manufacturing unit in Iran was assessed by WBGT (Wet Bulb Globe Temperature), CET (Corrected Effective Temperature), HSI (Heat Stress Index) and AET (Allowable Exposure Time) indexes. They verify positive accordance between the results of the three former indexes and negative correlation between AET and the others. Based on the observed values of $8 \mathrm{~h}$ measurements, high levels of workload and thermal stress assessed with the WBGT were revealed, accompanied by losses of productivity. In order to avoid heat stress occurrences in the hottest workplaces of glass manufacturing units, they suggest following both ACGIH and NIOSH recommendations. d'Ambrosio Alfano et al. ${ }^{7)}$ underlined the main issues about the WBGT index as a screening method for the evaluation of heat stress conditions. Hoorfarasat et $a l .{ }^{26)}$ considered a glass manufacturing plant and analysed the correlations of the heat strain score index (HSSI) and the WBGT index with physiological parameters (core body temperature, heart rate and blood pressure) in order to determine the reliability of the former. In Iran, Beheshti et $a{ }^{27}{ }^{27}$ evaluated the heat stress potential of several activities using the WBGT index and relate its value with the loss of performance when working in indoor high-temperature workplaces and Mohraz et al. ${ }^{28)}$ addressed the past and future trends of heat stress on the basis of the WBGT index. In Japan, Susuki-Parker and Kusaka ${ }^{29)}$ made future projections of labour hours in Osaka and Tokyo based on the WBGT index through simulations using multi-period dynamical downscale approach.

These papers show contributions from different parts of the world, thus enhancing that this kind of heat exposure is in fact a global issue. Furthermore, these very recent scientific papers prove that, despite some decades of studies on this matter, there is still work to be done. This afforded the authors the motivation to engage the task of document- 
ing the Portuguese reality on this matter. The case of the ceramic industry was already characterised with both the WBGT $^{10)}$ index and the PHS ${ }^{16)}$ model. This effort in mustering new data will continue as new activity fields are added to the already existing database. However, it must be emphasized that the authors have been facing an increasing opposition by CEOs to carry out studies in occupational settings, namely in working environments characterized by frequent exposures to extreme conditions. If this scenario spreads to other countries, or other kind of difficulties are raised, as already stressed in the assessment of other environments, like technical spaces onboard ships ${ }^{30,31)}$, it will most probably become more unusual to find in the literature detailed analysis of real environments which are so needed and welcomed, namely in order to validate current and/or future models. In this paper the actual scenario of the Portuguese glass industry is assessed with a screening method, the WBGT index, but also with a robust and validated method based on experimental basis, the PHS model.

\section{Methods}

In the following paragraphs, some details regarding the WBGT index and the PHS model are presented as well as measurement and estimation procedures, namely about the physical and individual parameters, the measurement specifications, the industrial units and the workplaces and the data used for the calculations, and also details about the normalization of the WBGT index and of PHS parameters.

\section{WBGT index}

The Wet Bulb Globe Temperature (WBGT) index was initially proposed by Yaglou and Minard ${ }^{32)}$ and after some improvements was adopted by NIOSH in $1972^{33)}$ and by ISO as an international standard in $1989^{2)}$.

The comparison between the weighted mean value of the WBGT index and the reference values proposed $\mathrm{in}^{2)}$, shown in Table 1, suggests the occurrence of a heat stress condition. When the measured value is higher than the reference value, it is necessary to either reduce directly the heat stress at the workplace by appropriate methods, namely through control of the work environment, of the metabolic rate of the workers, of the time spent in the workplace and by using personal protective equipment, or by imposing or increasing a rest period preferably under less severe thermal environments.

\section{PHS model}

The PHS model, based on a thermal balance equation
Table 1. WBGT reference values (adapted from $^{2)}$ )

\begin{tabular}{ccc}
\hline Metabolic rate & \multicolumn{2}{c}{ WBGT reference values ${ }^{* *}\left({ }^{\circ} \mathrm{C}\right)$} \\
\cline { 2 - 3 } $\mathrm{M}\left(\mathrm{W} \mathrm{m}^{-2}\right)$ & Non-acclimatized & Acclimatized \\
\hline $\mathrm{M} \leq 65$ & 32 & 33 \\
$65<\mathrm{M} \leq 130$ & 29 & 30 \\
$130<\mathrm{M} \leq 200$ & 26 & 28 \\
$200<\mathrm{M} \leq 260$ & $22 ; 23^{*}$ & $25 ; 26^{*}$ \\
$\mathrm{M}>260$ & $18 ; 20^{*}$ & $23 ; 25^{*}$ \\
\hline
\end{tabular}

*Sensible air movement

** The values given have been established allowing for a maximum rectal temperature of $38^{\circ} \mathrm{C}$ for the persons concerned

of the human body, has been validated by data obtained from 909 experiments (672 laboratory and 237 field tests), where its capability to provide reasonably accurate predictions was tested ${ }^{14,15)}$. The major limitation of PHS model is that it was only validated for clothing intrinsic thermal insulation $I_{c l} \leq 1.0$ clo $\left(1 \mathrm{clo}=0.155^{\circ} \mathrm{C} \mathrm{m}^{2} \mathrm{~W}^{-1}\right)$. If applied to subjects wearing clothing above this limit, such as firefighting clothing, it can generate unreasonable predictions ${ }^{17)}$. Also, the other limits of validity must be respected $^{3)}$.

The level of acceptability of the worker exposure to a specific hot environment is evaluated by comparing the parameters predicted by the PHS model with their corresponding limits, which are shown in Table 2 for acclimatized and non-acclimatized subjects. A predicted index $\left(w_{p}, S w_{p}, S W T O T g\right.$ and $\left.t_{r e}\right)$ with a value equal or greater than its limit $\left(w_{\max }, S w_{\max }, \mathrm{D}_{\max }\right.$ and $\left.t_{r e, \max }\right)$ suggests that the acceptable exposure time in the work environment has been exceeded, with a probable occurrence of a heat stress condition.

\section{Measurement and estimation procedures}

Physical parameters

The physical parameters of the environment were measured according to ${ }^{34)}$ using equipment from Brüel \& Kjær and from Testo.

The natural wet bulb $\left(t_{n w}\right)$, the $150 \mathrm{~mm}$ globe $\left(t_{g}\right)$ and the air $\left(t_{a}\right)$ temperatures were measured with the WBGTHeat Stress Monitor type 1219 from Brüel t Kjær which consists in a measurement unit, the WBGT Transducer (ref. MM0030), and in a data acquisition and monitoring unit named Heat Stress Monitor. The WBGT transducer consists of three separate resistance temperature sensing elements (Pt 100) according to ${ }^{2}$ requirements. The air and globe temperatures were also used to estimate the mean radiant temperature $\left(t_{r}\right)$ according to the expression suggested $\mathrm{in}^{34)}$. Those measurements were preceded by a sta- 
Table 2. Suggested limit values used in the PHS model (adapted from ${ }^{3,26)}$ )

\begin{tabular}{lcc}
\hline & Non-acclimatized & Acclimatized \\
\hline Maximum Wettedness, $\mathrm{W}_{\max }$ & 0.85 & 1.0 \\
\hline Maximum Sweat rate, $\mathrm{SW}_{\max }\left(\mathrm{W} \mathrm{m}^{-2}\right)$ & $(M-32) A_{\mathrm{Du}}$ & $1.25 \times(M-32) A_{\mathrm{Du}}$ \\
\hline Maximum Water loss $(\mathrm{g})$ for subjects that can drink freely: & & \\
- to protect $50 \%$ of workers $-\mathrm{D}_{\max 50}$ & $7.5 \%$ of body mass & $7.5 \%$ of body mass \\
- to protect 95\% of workers - $\mathrm{D}_{\max 95}$ & $5.0 \%$ of body mass & $5.0 \%$ of body mass \\
\hline Rectal temperature limit, $\mathrm{T}_{\mathrm{re}, \max }$ & $38^{\circ} \mathrm{C}$ & $38^{\circ} \mathrm{C}$ \\
\hline
\end{tabular}

bilization period of $30 \mathrm{~min}$.

The air velocity $\left(v_{a}\right)$ was measured with a frequency of $1 / 10 \mathrm{~Hz}$ with a hot sphere sensor from Testo (ref ${ }^{a} 0635$ 1049) connected to the data logger Testo $445\left(\mathrm{ref}^{\mathrm{a}} 0560\right.$ 4450). This data logger was also connected to a humidity transducer also from Testo ( ref $^{\mathrm{a}} 0636$ 9741).

The measurement of environmental parameters outdoors, namely the air temperature and the relative humidity $(R H)$, was carried out with the data logger Testo 175 $\mathrm{H} 2\left(\mathrm{ref}^{\mathrm{a}} 0563\right.$ 1758).

\section{Individual parameters}

In order to estimate the basic thermal insulation of ensembles $\left(I_{c l}\right)$ a questionnaire with a set of figures representing different types of garments was used and the workers were asked to identify the garments worn. Then, following ${ }^{35)}, I_{c l}$ was estimated by adding the values corresponding to each garment.

To estimate the activity level $(M)$, the methods of level II of accuracy of ${ }^{36,37)}$ were taken into account. The method consisted on adding the metabolic rates corresponding to the posture, the type of work, the body motion related to the work speed and the basal metabolic rate, for each single activity.

\section{Measurement specifications}

During field evaluations, the measurement specifications of the parameters, namely those related to the heterogeneity of the environment and the characteristics of the activity, have to be carefully considered. When the parameters do not have a constant value in the space surrounding the worker or when the workplaces present an important asymmetry in radiative terms, it is necessary to determine the WBGT index at three positions corresponding to the height of the head, abdomen and ankles in relation to the ground. In the workplaces under analysis all activities were conducted in the standing posture and so all the measurements were performed at $0.1,1.1$ and $1.7 \mathrm{~m}$ above the floor.

The time base to calculate the mean values of the WBGT index and the activity level is a period of work/resting of one hour. It is thus recommended that the measurements should take place during the period of maximum heat stress. The metabolism and the WBGT should correspond to weighted mean values along one hour as a function of the time and tasks developed by the worker during the period under analysis.

When it is not possible to determine the most representative hour of exposure, a longer period should be used. Therefore, the duration of the measurements in each workplace should last at least one hour, but this objective was not always achieved. In any case, due to the response time of the globe temperature sensor, the recording period shall always be higher than $20 \mathrm{~min}$, condition that was fulfilled. Among the 19 workplaces under analysis, in approximately $84 \%$ (16 out of 19 ) the recording period lasted 60 $\min$.

Industrial units and workplaces

In Portugal, a country with around 10.4 million of inhabitants, the economic activities are divided into classes called CAE (Classes of Economic Activity). The Glass Industry, broad designation of the activity sector adopted for the purpose of the present paper, is included in Class 23 (Manufacture of Other Non-metallic Mineral Products). This class embraces 5 sub-classes $(23,110,23,120,23,131$, 23,132 and 23,190) directed related to the activities under analysis. In 2014, the number of companies listed in class 23 was 3,145 and among these about 300 comprised glass industries. For the purpose of this study, a direct contact with a glass industry union was made and data about more than 41 industries was gathered. More than 5,000 workers were allocated to those industries, spread along Portugal $(2,422$ in the north, 1,565 in the centre and 1,038 in the south regions). In Portugal, this activity sector has an ancient tradition with both social and economic significance, particularly in the central provinces, namely Coimbra and Leiria, reason why these two provinces were selected for this study. 
Table 3. Details about the measurements and the workplaces

\begin{tabular}{|c|c|c|c|c|c|}
\hline $\begin{array}{l}\text { Industrial unit } \\
\text { reference number }\end{array}$ & Province & $\begin{array}{l}\text { Workplace } \\
\text { reference number }\end{array}$ & $\begin{array}{l}\text { Year/month of the } \\
\text { measurements }\end{array}$ & $\begin{array}{c}\text { Starting of the } \\
\text { measurements } \\
\text { [h:min] }\end{array}$ & $\begin{array}{c}\text { Duration of the } \\
\text { measurements } \\
\text { [min] }\end{array}$ \\
\hline \multirow{4}{*}{ Glass Industry 1} & \multirow{4}{*}{ Leiria } & G11 & \multirow{4}{*}{ 1994/November } & $12: 00$ & 30 \\
\hline & & G12 & & $13: 00$ & 60 \\
\hline & & G13 & & $15: 05$ & 60 \\
\hline & & G14 & & $17: 00$ & 60 \\
\hline \multirow{4}{*}{ Glass Industry 2} & \multirow{4}{*}{ Coimbra } & G21 & \multirow{4}{*}{ 2009/April } & $09: 10$ & 60 \\
\hline & & G22 & & $11: 30$ & 60 \\
\hline & & G23 & & $15: 30$ & 60 \\
\hline & & G24 & & $08: 10$ & 60 \\
\hline \multirow{3}{*}{ Glass Industry 3} & \multirow{3}{*}{ Leiria } & G31 & \multirow{3}{*}{ 2012/July } & $15: 00$ & 40 \\
\hline & & G32 & & $16: 19$ & 40 \\
\hline & & G33 & & $17: 50$ & 60 \\
\hline \multirow{4}{*}{ Glass Industry 4} & \multirow{4}{*}{ Leira } & G41 & \multirow{4}{*}{ 2015/September } & $10: 00$ & 60 \\
\hline & & G42 & & $11: 30$ & 60 \\
\hline & & G43 & & $14: 00$ & 60 \\
\hline & & G44 & & $15: 15$ & 60 \\
\hline \multirow{4}{*}{ Glass Industry 5} & \multirow{4}{*}{ Leiria } & G51 & \multirow{4}{*}{ 2015/September } & $10: 00$ & 60 \\
\hline & & G52 & & $11: 15$ & 60 \\
\hline & & G53 & & $12: 30$ & 60 \\
\hline & & G54 & & $14: 00$ & 60 \\
\hline
\end{tabular}

Table 3 shows details about the measurements and the workplaces. Five glass industries were considered, which comprised nineteen workplaces. Four MsC students contributed to this study that was started in 1994. A code of 3 digits is assigned to each workplace: the first digit is letter $\mathrm{G}$, representing the glass industry, followed by two numbers in which the first corresponds to the industrial unit studied and the second to the workplace, both sequentially numbered.

Input data for the PHS model

Table 4 shows data about physical and individual parameters. It is worth mentioning some details about these data:

a) In some cases, the estimation of the thermal insulation of the ensembles actually worn by the workers was not done and the reference value of ${ }^{2)}$ was assumed $\left(^{+}\right)$. This value also corresponds, approximately, to the mean value of the estimations carried out in the field. Therefore, and despite some exceptions that can be found in the glass industry and that will be mentioned ahead, the assumption of a reference value of 0.6 clo to globally characterize the thermal insulation of clothing in this activity sector can be considered as adequate;

b) Measurements outdoors were carried out only in the 2012 and 2015 evaluations (glass industries 3, 4 and 5);

c) In the 1994 (industry 1) and 2015 (industries 4 and 5) assessments, the air velocity was not measured and a value of $0.5 \mathrm{~m} / \mathrm{s}$ was assumed $\left({ }^{* *}\right)$. This value corresponds to the mean value of the measurements performed in industries 2 and 3 ;

d) The values of the partial pressure of water vapour were estimated from the outdoors environmental parameters air temperature and relative humidity, assuming negligible the production of water vapour inside the industrial units and, since natural ventilation processes were observed in all the industrial units visited the total pressure indoors and outdoors were also assumed equal. In the 1994 (industry 1) and 2009 (industry 2) assessments, the outdoor conditions were not measured; therefore, for the latter, hourly and daily Portuguese climatic information measured by the meteorological station closest to factory 2 was considered. Unfortunately, this information was not available for the case of 1994 fieldwork. This drawback was overcome by considering the reference values of the Portuguese climate database for respective day and location. In the 2012 and 2015 evaluations (glass industries 3, 4 and 5) the air temperature and the relative humidity were measured.

It should be emphasized that ${ }^{3)}$ defines ranges of applicability of the PHS model. The present sample shows that workplaces $\mathrm{G} 13$ and $\mathrm{G} 14$ have air temperature values higher than $50^{\circ} \mathrm{C}$, upper limit of $t_{a}$ stated in the mentioned 
Table 4. Physical and individual parameters of the workplaces

\begin{tabular}{|c|c|c|c|c|c|c|c|c|c|c|c|c|}
\hline \multirow{3}{*}{$\begin{array}{c}\text { Workplace } \\
\text { reference } \\
\text { number }\end{array}$} & \multicolumn{2}{|c|}{ Conditions outdoors } & \multirow{2}{*}{\multicolumn{2}{|c|}{\begin{tabular}{cc}
\multicolumn{2}{c}{ Individual parameters } \\
Clothing & \\
thermal & Metabolism \\
insulation & {$[\mathrm{W}]$} \\
[clo] &
\end{tabular}}} & \multicolumn{3}{|c|}{ WBGT data } & \multicolumn{5}{|c|}{ Physical parameters } \\
\hline & $\begin{array}{c}\text { Temperature } \\
\text { outdoors }\end{array}$ & $\begin{array}{c}\text { Humidity } \\
\text { outdoors } \\
{[\%]}\end{array}$ & & & $\begin{array}{l}\text { Metabolic } \\
\text { class. }\end{array}$ & $\begin{array}{l}\text { WBGT } \\
\text { ref. }\end{array}$ & $\begin{array}{c}\text { WBGT } \\
\text { weighted. } \\
{\left[{ }^{\circ} \mathrm{C}\right]}\end{array}$ & $\begin{array}{c}\text { Air } \\
\text { temperature } \\
{\left[{ }^{\circ} \mathrm{C}\right]}\end{array}$ & $\begin{array}{c}\text { Natural } \\
\text { wet bulb } \\
\text { temperature } \\
{\left[{ }^{\circ} \mathrm{C}\right]}\end{array}$ & $\begin{array}{c}\text { Globe } \\
\text { temperature } \\
{\left[{ }^{\circ} \mathrm{C}\right]}\end{array}$ & $\begin{array}{c}\text { Partial } \\
\text { pressure } \\
\text { of water } \\
\text { vapour } \\
{[\mathrm{kPa}]}\end{array}$ & $\begin{array}{c}\text { Air } \\
\text { velocity } \\
{[\mathrm{m} / \mathrm{s}]}\end{array}$ \\
\hline & $t_{a, \text { out }}\left[{ }^{\circ} \mathrm{C}\right]$ & $R H_{\text {out }}$ & $I_{c l}[\mathrm{clo}]$ & $M[\mathrm{~W}]$ & & $\begin{array}{c}W B G T_{\text {ref }} \\
{\left[{ }^{\circ} \mathrm{C}\right]}\end{array}$ & $\begin{array}{c}W B G T \\
{\left[{ }^{\circ} \mathrm{C}\right]}\end{array}$ & $\begin{array}{c}t_{a} \\
{\left[{ }^{\circ} \mathrm{C}\right]}\end{array}$ & $\begin{array}{c}t_{n w} \\
{\left[{ }^{\circ} \mathrm{C}\right]} \\
\end{array}$ & $\begin{array}{c}t_{g} \\
{\left[{ }^{\circ} \mathrm{C}\right]}\end{array}$ & $\begin{array}{c}p_{a} \\
{[\mathrm{kPa}]}\end{array}$ & $\begin{array}{c}v_{a} \\
{[\mathrm{~m} / \mathrm{s}]}\end{array}$ \\
\hline G11 & 15.4 & 81.0 & $0.6^{+}$ & 297 & 2 & 28.0 & 35.1 & 29.1 & 22.4 & 64.7 & 1.417 & $0.5^{* *}$ \\
\hline G12 & 16.5 & 78.0 & $0.6^{+}$ & 239 & 2 & 28.0 & 30.3 & 32.1 & 21.4 & 51.0 & 1.464 & $0.5^{* *}$ \\
\hline G13* & 16.8 & 77.0 & $0.6^{+}$ & 239 & 2 & 28.0 & 38.3 & 60.2 & 27.8 & 63.0 & 1.473 & $0.5^{* *}$ \\
\hline G14* & 15.0 & 83.0 & $0.6^{+}$ & 239 & 2 & 28.0 & 47.1 & 61.1 & 31.5 & 83.3 & 1.415 & $0.5^{* *}$ \\
\hline G21 & 15.2 & 69.0 & $0.6^{+}$ & 297 & 2 & 28.0 & 35.5 & 37.5 & 25.2 & 59.4 & 1.192 & 0.8 \\
\hline G22 & 20.5 & 49.0 & $0.6^{+}$ & 268 & 1 & 30.0 & 20.1 & 24.4 & 17.2 & 26.8 & 1.182 & 0.3 \\
\hline G23 & 22.8 & 41.0 & $0.6^{+}$ & 268 & 2 & 28.0 & 32.7 & 39.1 & 24.6 & 51.6 & 1.138 & 0.4 \\
\hline G24 & 13.1 & 77.0 & $0.6^{+}$ & 414 & 3 & 26.0 & 22.2 & 25.0 & 18.7 & 30.4 & 1.161 & 0.6 \\
\hline G31 & 22.0 & 52.0 & 0.7 & 220 & 1 & 30.0 & 34.5 & 33.9 & 22.5 & 62.5 & 1.375 & 0.2 \\
\hline G32 & 22.0 & 49.0 & 0.7 & 220 & 1 & 30.0 & 26.7 & 31.8 & 20.8 & 40.4 & 1.295 & 0.6 \\
\hline G33 & 22.0 & 52.0 & 0.7 & 226 & 1 & 30.0 & 31.9 & 41.0 & 38.7 & 51.2 & 1.375 & 0.5 \\
\hline G41 & 20.0 & 76.0 & 0.5 & 297 & 2 & 28.0 & 29.6 & 32.7 & 25.7 & 38.7 & 1.777 & $0.5^{* *}$ \\
\hline $\mathrm{G} 42$ & 22.0 & 69.0 & 0.5 & 176 & 1 & 30.0 & 33.8 & 31.0 & 26.5 & 40.3 & 1.824 & $0.5^{* *}$ \\
\hline $\mathrm{G} 43$ & 24.0 & 61.0 & 0.6 & 297 & 1 & 30.0 & 29.3 & 28.2 & 26.0 & 32.0 & 1.820 & $0.5^{* *}$ \\
\hline G44 & 24.0 & 59.0 & 0.6 & 414 & 3 & 25.0 & 35.8 & 34.8 & 33.7 & 38.2 & 1.760 & $0.5^{* *}$ \\
\hline G51 & 19.0 & 69.0 & 0.6 & 297 & 2 & 28.0 & 31.9 & 29.6 & 25.3 & 37.3 & 1.516 & $0.5^{* *}$ \\
\hline G52 & 20.0 & 66.0 & 0.5 & 297 & 2 & 28.0 & 30.0 & 28.7 & 25.3 & 33.3 & 1.543 & $0.5^{* *}$ \\
\hline G53 & 21.0 & 63.0 & 0.5 & 176 & 1 & 30.0 & 38.0 & 37.2 & 36.2 & 39.9 & 1.567 & $0.5^{* *}$ \\
\hline G54 & 22.0 & 61.0 & 0.6 & 176 & 1 & 30.0 & 34.8 & 33.7 & 29.8 & 37.4 & 1.613 & $0.5^{* *}$ \\
\hline
\end{tabular}

* Out of the validity of the PHS model.

**Mean value of the measurements performed in industries 2 and 3 .

${ }^{+}$Mean value of $I_{c l}$ based on the estimations carried out in the field.

standard. Despite this scenario the calculations were performed but, in these cases, it is recommended to use the PHS model with caution and to pay particular attention to the workers exposed to such environments by means of individual medical survey. Furthermore, in these cases, the objectives and procedures defined by the Expertise stage of ISO $15265^{4)}$ is duly recommended, since it deals with highly complex thermal working circumstances and require sophisticated or special measurements.

Workplaces G11, G21 and G31 also deserve a particular mention due to significant differences between the mean radiant and air temperatures. According to ${ }^{3)}$, workplaces with $t_{r}-t_{a}$ values higher than $60^{\circ} \mathrm{C}$ are outside the range of applicability of the PHS model. In the present sample this condition was not verified, but in those workplaces very high differences were observed $\left(\mathrm{G} 11: 55.7^{\circ} \mathrm{C} ; \mathrm{G} 21\right.$ : $\left.50.6^{\circ} \mathrm{C} ; \mathrm{G} 31: 45.3^{\circ} \mathrm{C}\right)$.

The present data shows that in glass industries the possibility of exceeding the limits of applicability of the PHS model is real. Hence, more research work and experimental data is required to increase the actual sample, thus allowing future revisions to take into account even more extreme industrial environments.

It is also worth mentioning that the field assessments put in evidence very different continuous exposure times. Typically, continuous exposures higher than $2 \mathrm{~h}$ are difficult to find in the more severe thermal environments, but one hour exposure is quite common. Therefore, in order to be able to compare results and to simulate a realistic exposure, this was the value admitted for the PHS calculations. Thus, it should be underlined that the results that are presented refer to the values obtained after an exposure period of 60 min. Moreover, a $74 \mathrm{~kg}$ of body mass, a height of $1.69 \mathrm{~m}$, reference anthropometric values of Portuguese workers ${ }^{38)}$, a standing posture, an acclimatized condition and a freely water replacement were assumed.

\section{Normalization of the WBGT index and of PHS parameters}

In thermophysiological terms, the WBGT index is used for the assessment of the thermal environment and not for a direct evaluation of the thermal state of an individual. On the other hand, the PHS evaluates both but it is focused 
Table 5. Physical parameters of the workplaces

\begin{tabular}{|c|c|c|c|c|c|c|c|c|c|c|c|c|}
\hline & \multicolumn{4}{|c|}{ Air temperature, $t_{a}\left[{ }^{\circ} \mathrm{C}\right]$} & \multicolumn{4}{|c|}{$\begin{array}{l}\text { Natural wet bulb } \\
\text { temperature, } t_{n w}\left[{ }^{\circ} \mathrm{C}\right]\end{array}$} & \multicolumn{4}{|c|}{$\begin{array}{c}\text { Globe temperature, } t_{g} \\
{\left[{ }^{\circ} \mathrm{C}\right]}\end{array}$} \\
\hline & Max & Mean & Min & SD & $\operatorname{Max}$ & Mean & Min & SD & Max & Mean & Min & SD \\
\hline G11 & 29.9 & 29.1 & 27.4 & 0.6 & 24.8 & 22.4 & 20.9 & 0.7 & 68.0 & 64.7 & 55.9 & 4.0 \\
\hline G12 & 34.1 & 32.1 & 30.0 & 0.8 & 21.9 & 21.4 & 21.0 & 0.2 & 51.8 & 51.0 & 49.7 & 0.5 \\
\hline G13* & 65.0 & 60.2 & 56.0 & 2.5 & 28.8 & 27.8 & 27.0 & 0.5 & 65.6 & 63.0 & 60.5 & 1.6 \\
\hline G14* & 62.2 & 61.1 & 60.1 & 0.4 & 31.8 & 31.5 & 31.0 & 0.1 & 84.1 & 83.3 & 78.5 & 0.8 \\
\hline $\mathrm{G} 21$ & 48.0 & 37.5 & 32.8 & 2.6 & 27.3 & 25.2 & 23.2 & 1. & 69.1 & 59.4 & 52.8 & 4.6 \\
\hline G22 & 28.0 & 24.4 & 23.4 & 0.9 & 19.0 & 17.2 & 16.5 & 0.7 & 28.1 & 26.8 & 26.2 & 0.5 \\
\hline G23 & 40.5 & 39.1 & 37.7 & 0.6 & 25.3 & 24.6 & 23.9 & 0.3 & 52.6 & 51.6 & 50.5 & 0.5 \\
\hline G24 & 26.3 & 25.0 & 24.0 & 0.4 & 21.7 & 18.7 & 18.2 & 0.4 & 31.4 & 30.4 & 29.6 & 0.5 \\
\hline G31 & 36.1 & 33.9 & 31.6 & 1.1 & 23.4 & 22.5 & 20.7 & 0.5 & 64.9 & 62.5 & 42.2 & 4.2 \\
\hline G32 & 32.7 & 31.8 & 31.2 & 0.4 & 21.3 & 20.8 & 20.5 & 0.2 & 40.8 & 40.4 & 39.7 & 0.3 \\
\hline G33 & 42.5 & 41.0 & 39.4 & 0.6 & 39.5 & 38.7 & 37.0 & 0.4 & 52.2 & 51.2 & 49.1 & 0.4 \\
\hline G41 & 33.7 & 32.7 & 32.2 & 0.3 & 26.8 & 25.7 & 24.5 & 0. & 39.3 & 38.7 & 38.0 & 0.3 \\
\hline G42 & 31.9 & 31.0 & 30.5 & 0.3 & 28.1 & 26.5 & 25.3 & 0. & 42.1 & 40.3 & 39.0 & 0.7 \\
\hline G43 & 29.0 & 28.2 & 27.6 & 0.4 & 29.1 & 26.0 & 24.9 & 0.7 & 33.9 & 32.0 & 29.9 & 1.1 \\
\hline G44 & 35.5 & 34.8 & 33.6 & 0.4 & 36.6 & 33.7 & 30.7 & 1.2 & 39.4 & 38.2 & 31.2 & 1.0 \\
\hline G51 & 31.4 & 29.6 & 27.7 & 0.8 & 27.3 & 25.3 & 24.1 & 0.7 & 40.4 & 37.3 & 35.9 & 1.0 \\
\hline G52 & 29.8 & 28.7 & 27.9 & 0.4 & 27.8 & 25.3 & 24.2 & 0.8 & 35.5 & 33.3 & 31.9 & 0.7 \\
\hline G53 & 38.5 & 37.2 & 32.3 & 1.4 & 38.0 & 36.2 & 34.0 & 0.9 & 40.7 & 39.9 & 37.0 & 0.7 \\
\hline G54 & 35.3 & 33.7 & 32.7 & 0.6 & 31.1 & 29.8 & 28.4 & 0.6 & 39.0 & 37.4 & 36.3 & 0.7 \\
\hline
\end{tabular}

* Out of the validity of the PHS model.

on the thermal condition of the worker. In order to outline these statements and the present analysis, the values obtained with both methods were normalized according to the following expressions:

$$
\begin{aligned}
& \mathrm{R}_{\text {WBGT }}=\frac{\text { WBGT }}{W \mathrm{WGT}_{\mathrm{ref}}} \quad \mathrm{R}_{\mathrm{req}}=\frac{\mathrm{P}_{\mathrm{req}}}{\mathrm{P}_{\max }} \quad \mathrm{R}_{\mathrm{p}}=\frac{\mathrm{P}_{\mathrm{p}}}{\mathrm{P}_{\max }} \\
& \mathrm{RT}_{\mathrm{re}}=\frac{\left(\mathrm{t}_{\mathrm{re}}-\mathrm{t}_{\mathrm{re}, \mathrm{n}}\right)}{\left(\mathrm{t}_{\mathrm{re}, \max }-\mathrm{t}_{\mathrm{re}, \mathrm{n}}\right)}
\end{aligned}
$$

where $\mathrm{P}_{\mathrm{i}}$ is the PHS generic parameter [maximum $\left(\mathrm{P}_{\max }\right)$, required $\left(\mathrm{P}_{\text {req }}\right.$ ) or predicted $\mathrm{P}_{\mathrm{p}}$ ) values] and $t_{r e, n}$ is the neutral rectal temperature. The maximum value of PHS parameters $w_{\max }, S w_{\max }$ and $t_{r e, \max }$ is independent of the situation under study while the WBGT reference value (WBGT ${ }_{\text {ref }}$ ) accounts the activity level ${ }^{3,7,14)}$. On the other hand, the maximum evaporative heat rate $\left(E_{\max }\right)$ depends on the skin temperature of the subject under each situation ${ }^{3,7,14)}$ For a consistent analysis, the neutral rectal temperature must be specified considering the fact that the regulation of the body temperature is dependent of the activity level. For this purpose, the equation of Saltin and Hermansen ${ }^{39)}$ is used, where $\mathrm{t}_{\mathrm{re}, \mathrm{n}}=36.6+0.002 \mathrm{M}$, with $\mathrm{M}$ in Watts.

\section{Results}

In the next paragraphs, the results of the air, the natural wet-bulb and the globe temperatures and of the WBGT index and the PHS model are presented.

\section{Physical parameters}

Table 5 shows the maximum, the mean and the minimum weighted values of the dry bulb air temperature $\left(t_{a}\right)$, the natural wet bulb $\left(t_{n w}\right)$ and the globe $\left(t_{g}\right)$ temperatures, as well as the standard deviation (SD) values of those parameters (for a $95 \%$ confidence level).

The air temperature results show that the highest and lowest maximum values were $65.0^{\circ} \mathrm{C}(\mathrm{G} 13)$ and $26.3^{\circ} \mathrm{C}$ (G24). Five of the nineteen workplaces under analysis have maximum air temperature values higher than $40^{\circ} \mathrm{C}$. The highest mean value was $61.1^{\circ} \mathrm{C}(\mathrm{G} 14)$ and the lowest was $24.4^{\circ} \mathrm{C}(\mathrm{G} 22)$. The highest and lowest minimum values were $60.1^{\circ} \mathrm{C}(\mathrm{G} 14)$ and $23.4^{\circ} \mathrm{C}(\mathrm{G} 22)$, respectively. The SD values ranged between 0.3 (G41 and G42) and 2.6 (G21).

In the case of the natural wet bulb temperature four workplaces present maximum, mean and minimum values higher than $30^{\circ} \mathrm{C}(\mathrm{G} 14, \mathrm{G} 33, \mathrm{G} 44$ and G53). In these cases, the highest maximum corresponds to workplace 


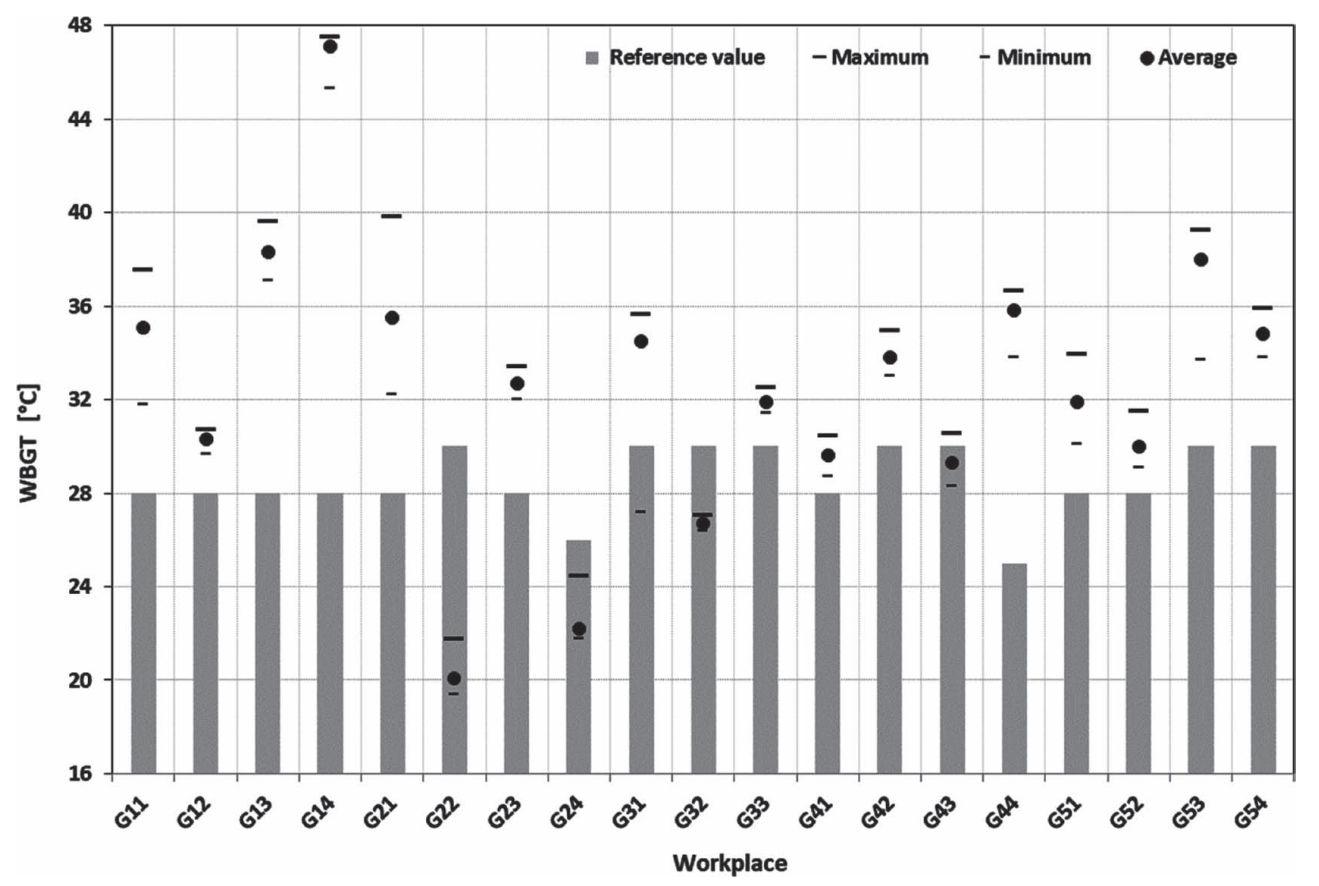

Fig. 1. Weighted WBGT and reference values.

(G33) with $39.5^{\circ} \mathrm{C}$ and lowest minimum to workplace (G44) with $30.7^{\circ} \mathrm{C}$. The maximum mean value was $38.7^{\circ} \mathrm{C}$ (G33) and the lowest $17.2^{\circ} \mathrm{C}(\mathrm{G} 22)$. A reference is also due to workplace (G44) which presents the highest difference between the maximum and minimum values $\left(5.9^{\circ} \mathrm{C}\right)$. The lowest and highest SD values were $0.1{ }^{\circ} \mathrm{C}$ (G14) and 1.2 (G44), respectively.

The results of the globe temperature show that eight workplaces present mean and maximum values higher than $50^{\circ} \mathrm{C}$ (G11, G12, G13, G14, G21, G23, G31 and G33). The highest maximum was $84.1^{\circ} \mathrm{C}$ (G14) and the lowest minimum was $26.2^{\circ} \mathrm{C}(\mathrm{G} 22)$. A special reference is due to the first glass industry assessed where the minimum value of the globe temperature was $49.7^{\circ} \mathrm{C}$, and particularly to workplace G14. In this case, at the head level, the maximum, mean and minimum values recorded were 102.3, 102.2 and $96.8^{\circ} \mathrm{C}$. The corresponding values at the abdomen level were $81.6,80.5$ and $77.2^{\circ} \mathrm{C}$, and at the ankle level were $71.4,70.5$ and $62.8^{\circ} \mathrm{C}$, respectively. Workplace G21 presents the highest difference between the maximum and minimum values $\left(16.3^{\circ} \mathrm{C}\right)$, showing that, at least in radiative terms, during the period assessed important variations were observed. Accordingly, this workplace presents the maximum $\mathrm{SD}$ value $\left(4.6^{\circ} \mathrm{C}\right)$ but a special reference is also due to workplaces $\mathrm{G} 11$ and G31 with SD values equal or higher than 4.0 . The minimum SD value was $0.3^{\circ} \mathrm{C}$ and was obtained in two workplaces (G32 and G41).

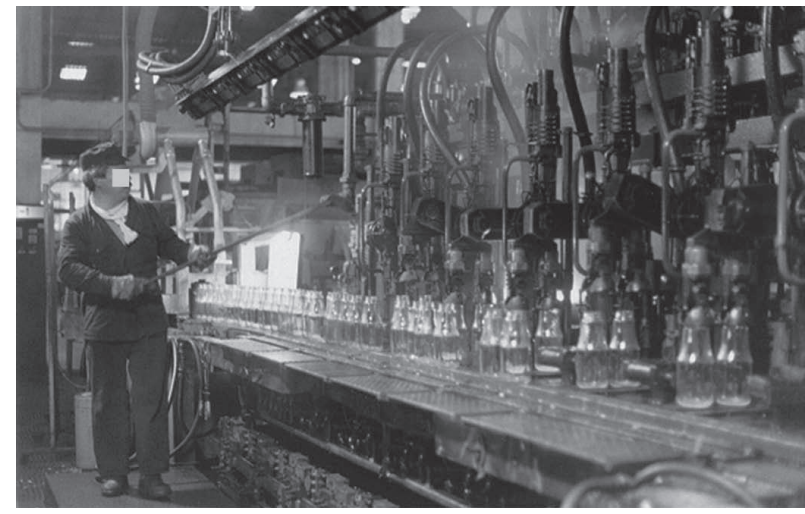

Fig. 2. Workplace G14.

\section{$W B G T$}

Figure 1 shows the results of the weighted WBGT as well as the WBGT reference values. The latter are presented in a grey bar in order to obtain a quick perception of the workplaces with a heat stress potential.

If the maximum values measured at each workplace are considered, one can conclude that sixteen out of nineteen sites have measured values higher than the reference limits proposed $\mathrm{by}^{2)}$, hence presenting potential situations for heat stress. However, if the mean values are assumed, then the number of potential heat stress cases decreases only one workplace, hence showing that almost $80 \%$ of the workplaces of the glass industry under analysis are prone 


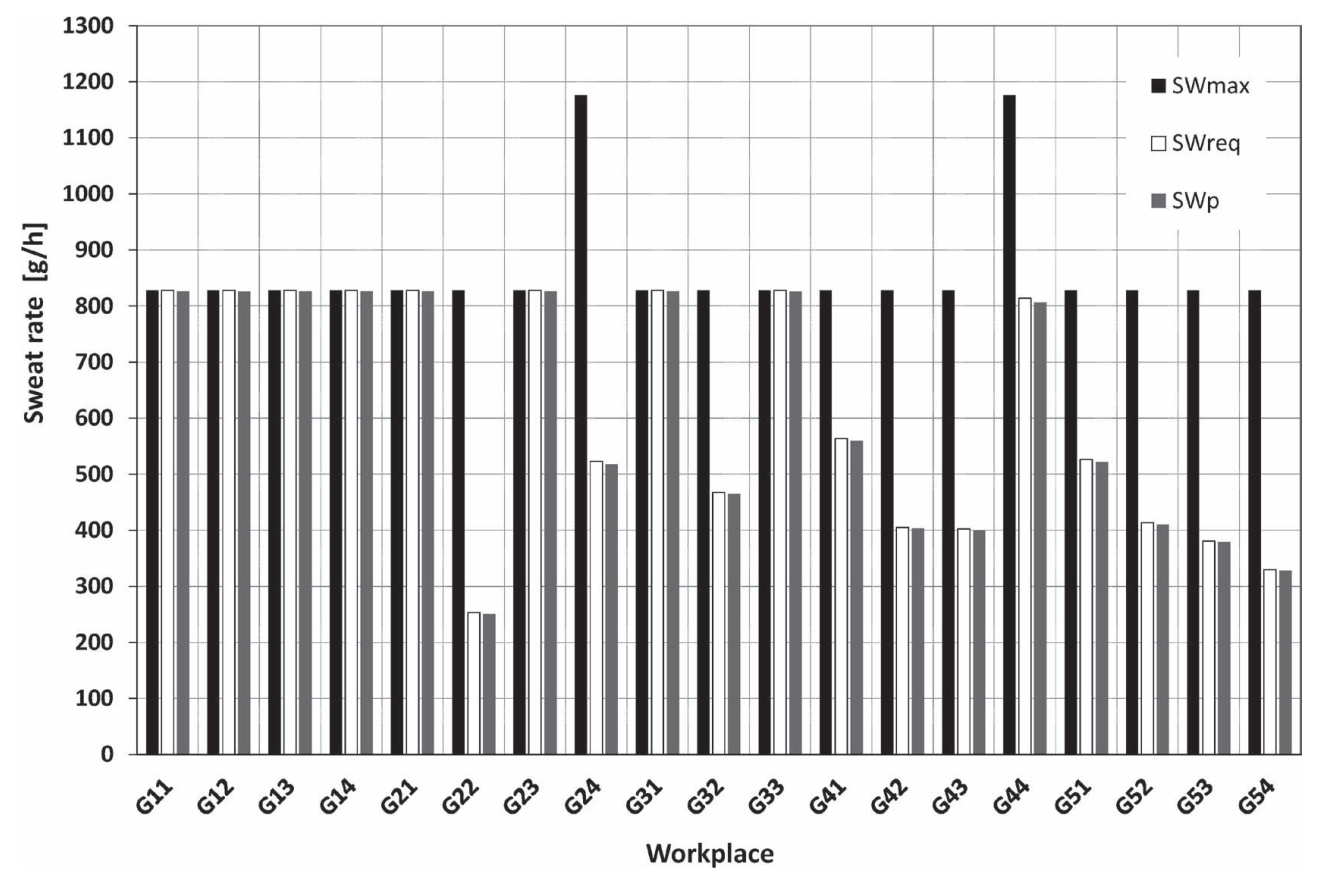

Fig. 3. Maximum, required and predicted sweat rate values.

to heat stress conditions. The maximum WBGT values varied between $21.7^{\circ} \mathrm{C}(\mathrm{G} 22)$ and $47.5^{\circ} \mathrm{C}(\mathrm{G} 14)$ while the mean ranged between $20.1^{\circ} \mathrm{C}$ and $47.1^{\circ} \mathrm{C}$, obtained in the same workplaces. Sixteen workplaces have mean values higher than $28^{\circ} \mathrm{C}$ (reference value of class 2 of metabolic rate $^{2)}$ ) and fourteen have mean values higher or equal to $30^{\circ} \mathrm{C}$ (reference value of class 1 of metabolic rate ${ }^{2)}$ ).

Special references are due to workplaces G14 with a minimum value equal to $45.3^{\circ} \mathrm{C}$ and to $\mathrm{G} 21$ with a difference between the maximum and the minimum values equal to $7.6^{\circ} \mathrm{C}$. A mention is also necessary to workplace G43 because in this case the WBGT mean value $\left(29.3^{\circ} \mathrm{C}\right)$ is close to the reference value $\left(30^{\circ} \mathrm{C}\right)$. Whenever this scenario happens a heat stress condition may arise due to an increase of the metabolic rate of the activity or due to an increase of the physical parameters of the environment. It is also important to emphasize that no corrections are being considered in the WBGT reference values due to clothing ensembles actually worn by the workers. In fact, Fig. 2, which refers to workplace G14, clearly puts in evidence that it is really necessary to adopt, in some workplaces, ensembles with higher thermal insulations, not because it is required for that specific purpose, but because it is demanded to protect the worker from injuries that can easily arise due to the characteristics of the activity. Therefore, it should be stressed that the WBGT reference values defined $\mathrm{in}^{2)}$ can only be adequately considered whenever the intrinsic clothing insulation of the ensembles is close to 0.6 clo, which is, as shown in Table 4, more or less the cases of the present study.

\section{PHS}

The PHS model enables a detailed analysis of the working conditions by providing an extensive amount of data. For the present purposes, the PHS indexes sweat rate $(S w$, $\left.\mathrm{g} \mathrm{h}^{-1}\right)$, evaporative heat rate $\left(E, \mathrm{~W} \mathrm{~m}^{-2}\right)$, skin wettedness $\left(w\right.$, dimensionless) and rectal temperature $\left(t_{r e},{ }^{\circ} \mathrm{C}\right)$ are presented.

\section{Sweat rate}

Figure 3 shows the results of the maximum $\left(S w_{\max }\right)$, the required $\left(S w_{\text {req }}\right)$ and the predicted $\left(S w_{p}\right)$ sweat rates. Eight workplaces show values of $S w_{\text {req }}$ equal to $S w_{\max }$. It is desirable that $S w_{\text {req }}$ is lower than $S w_{\max }$ but, whenever $S w_{\text {req }}$ is higher than $S w_{\max }$, the model imposes an equality of those values. This scenario indicates harsh conditions in the workplace and for the present data those eight workplaces show $S w_{\max }$ and $S w_{\text {req }}$ values equal to $828.1 \mathrm{~g} / \mathrm{h}$. Moreover, in these workplaces the predicted and maximum values are very close to each other, meaning that the thermoregulatory system of the human body reveals difficulties in responding efficiently to the environmental conditions to which it is exposed.

The highest value of $S w_{\max }$ was equal to $1176.1 \mathrm{~g} / \mathrm{h}$ and was obtained in workplaces G24 and G44. However, in workplace G24, the difference between $S w_{\max }$ and $S w_{p}$ is 


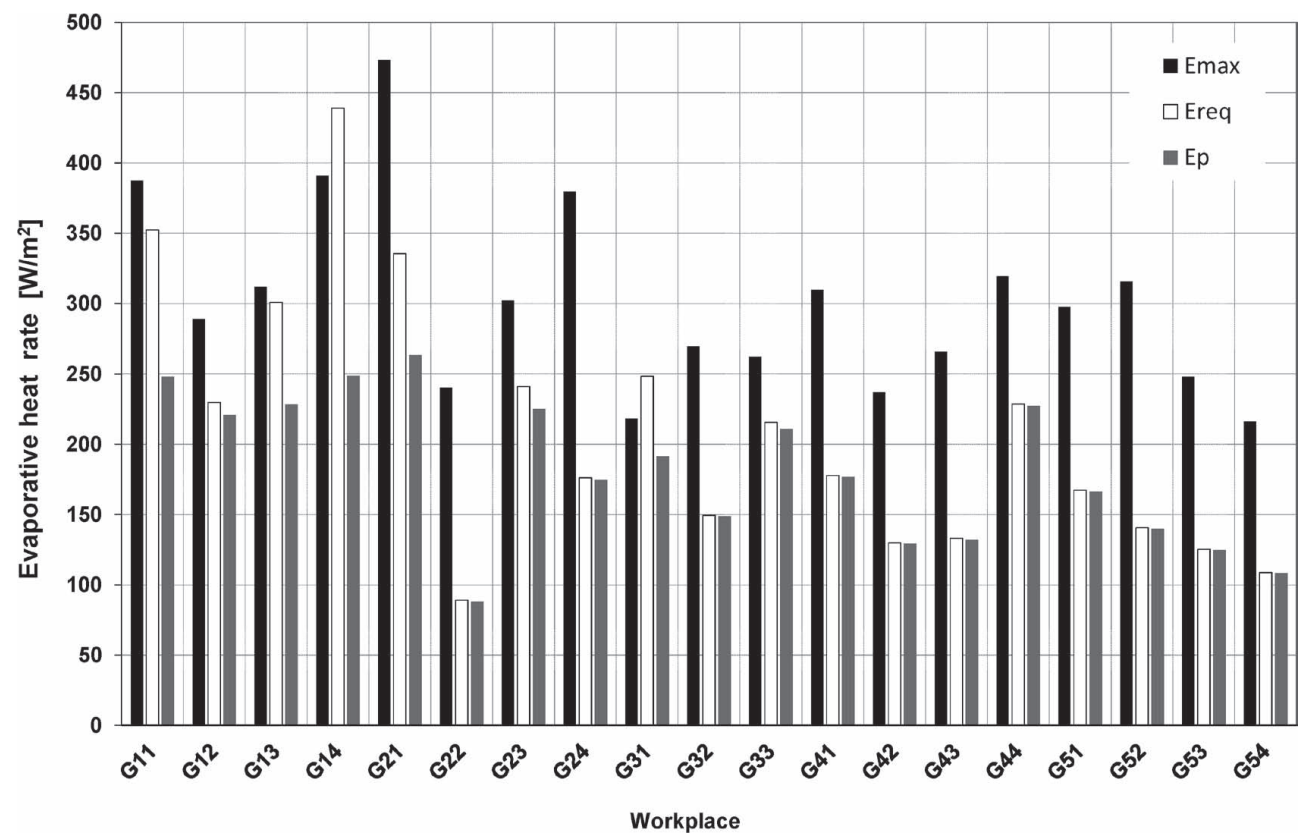

Fig. 4. Maximum, required and predicted evaporative heat rate values.

equal to $658.5 \mathrm{~g} / \mathrm{h}$ followed workplace G22 that also presents a high difference between $S w_{\max }$ and $S w_{p}$, reaching $577.4 \mathrm{~g} / \mathrm{h}$. Whenever significant differences occur, it means that the human body is in a better condition to cope with the thermal environment and hence the thermoregulatory system has the ability to respond efficiently to the environmental conditions.

The sweat rate gives an indication about the amount of heat that can be lost through the mechanism of evaporation. The sweat rate and the evaporative heat rate are thus linked and the results of the latter are addressed in the following section.

\section{Evaporative heat rate}

The rate of heat storage in the human body depends on a thermal balance involving heat gains and losses with the environment and internal heat generation. Among the losses, the evaporation heat rate plays an important role in the maintenance of the human body thermal equilibrium in situations of exposures to hot or very hot environments. The maximum $\left(E_{\max }\right)$, the required $\left(E_{\text {req }}\right)$ and the predicted $\left(E_{p}\right)$ evaporative heat rates for each workplace are shown in Fig. 4.

The values of $E_{\max }$ ranged between $216.2 \mathrm{~W} / \mathrm{m}^{2}$ (G54) and $473.5 \mathrm{~W} / \mathrm{m}^{2}(\mathrm{G} 21)$. The corresponding range for the $E_{\text {req }}$ values lays between $89.0(\mathrm{G} 22)$ and $439.1 \mathrm{~W} / \mathrm{m}^{2}(\mathrm{G} 14)$ and for $E_{p}$ between $88.1(\mathrm{G} 22)$ and $263.5 \mathrm{~W} / \mathrm{m}^{2}(\mathrm{G} 21)$. The values of the difference $E_{\max }-E_{\text {req }}$ ranged between -48.2
$\mathrm{W} / \mathrm{m}^{2}$ (G14) and $+203.6 \mathrm{~W} / \mathrm{m}^{2}$ (G24). In the case of the difference $E_{\max }-E_{p}$ the highest value is $210.0 \mathrm{~W} / \mathrm{m}^{2}(\mathrm{G} 21)$.

\section{Skin wettedness}

Skin wettedness is a stress criterion with a maximum value $\left(w_{\max }\right)$ of 0.85 for non-acclimatized individuals and of 1.0 for acclimatized subjects ${ }^{3)}$. If the skin is totally wetted, then the skin wettedness is equal to one. Hence, the predicted skin wettedness $\left(w_{p}\right)$ cannot have a value higher than one, once the heat exchange by evaporation is limited to the body surface. However, the required skin wettedness $\left(w_{\text {req }}\right)$ can be higher than 1.0 and this happens when the required evaporative heat rate $\left(E_{\text {req }}\right)$ is higher than the maximum possible $\left(E_{\max }\right)$.

Figure 5 shows the results of the maximum, the required and the predicted skin wettednesses for acclimatized subjects, then $w_{\max }=1.0$ in all situations. It can be observed that, in the present sample, $w_{\text {req }}$ varied between 0.37 (G22) and 1.14 (G31) while $w_{p}$ ranged between $0.37(\mathrm{G} 22)$ and 0.88 (G31). It is noteworthy that four workplaces show $w_{\text {req }}$ values higher than 0.9 and among these two are higher than 1.0.

A favourable condition occurs when both the required and the predicted values of skin wettedness are lower than the maximum. In the present sample, this happens seventeen times. Moreover, eighteen workplaces show values of predicted skin wettedness lower than 0.85 . 


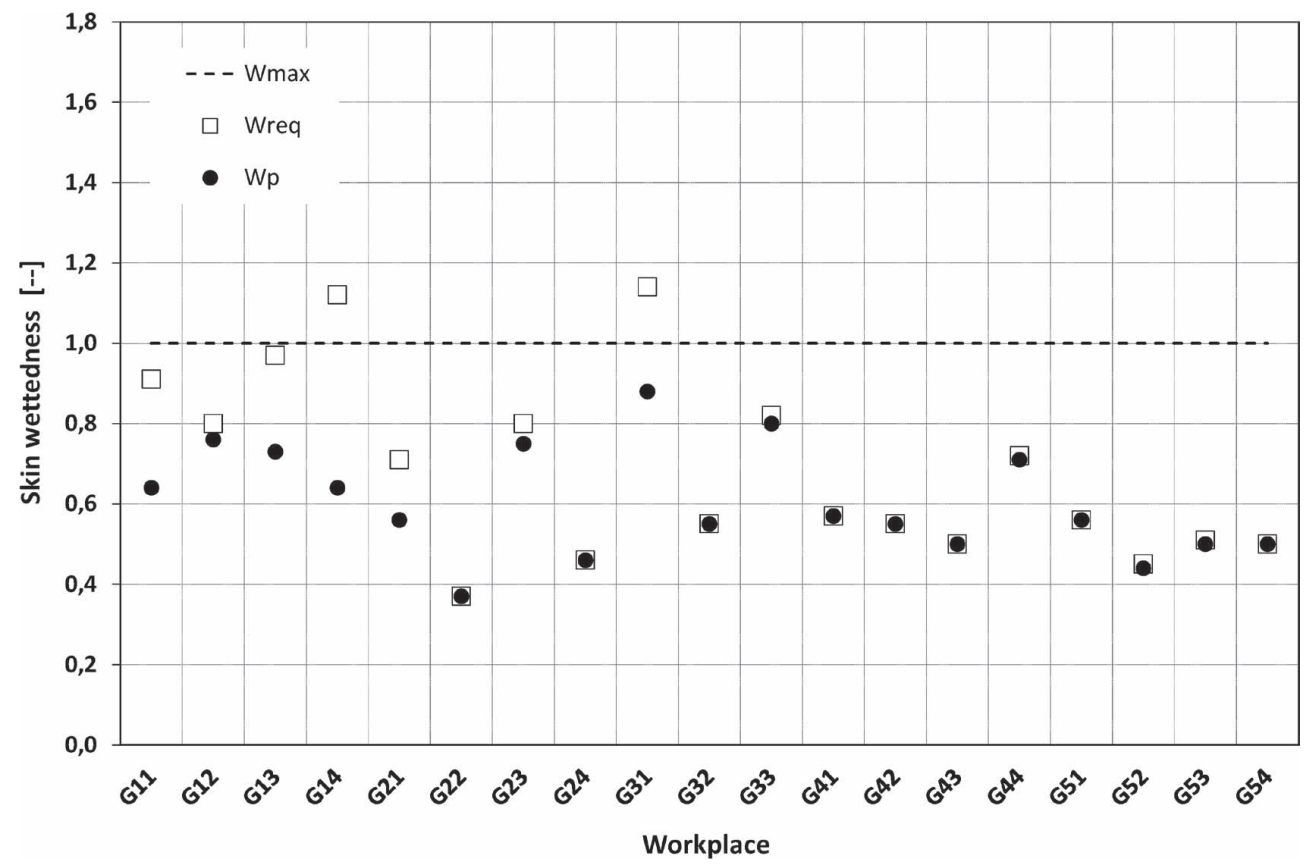

Fig. 5. Maximum, required and predicted skin wettedness values.

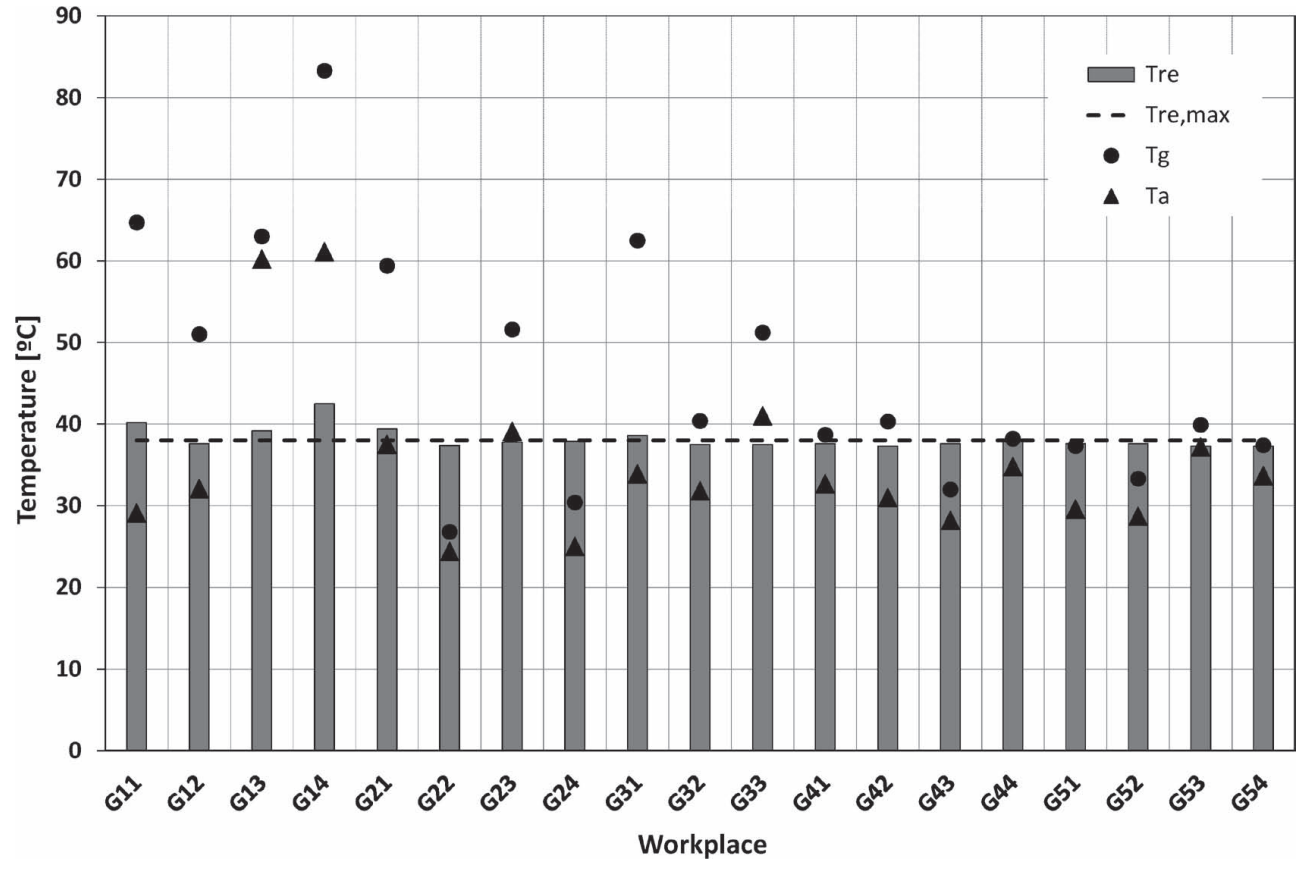

Fig. 6. Rectal and maximum rectal temperatures $v s$ measured globe and air temperature values.

Rectal temperature

The rectal temperature is frequently assumed as being representative of the thermal state of an individual, particularly in occupational activities. As the present study was developed in such environments, the analysis of the $t_{r e}$ results is thus important. Quoting WHO technical report $\mathrm{n}^{\mathrm{o}} 41240$ ) "it is generally from the rectal temperature that is estimated the time at which it is necessary to interrupt a short duration exposure to intense heat in laboratory", and "It is inadvisable for deep body temperature to exceed $38^{\circ} \mathrm{C}$ in prolonged daily exposure to heavy work". For this reason, it is important to emphasize the significance of that 
Table 6. Normalized values for WBGT index and PHS parameters

\begin{tabular}{|c|c|c|c|c|c|c|c|c|c|}
\hline & \multicolumn{5}{|c|}{ Potential of the environment for heat stress } & \multicolumn{4}{|c|}{ Worker heat stress $(t=60 \mathrm{~min})$} \\
\hline & $\mathrm{D}_{\text {lim, tre }}[\mathrm{min}]$ & $\mathrm{R}_{\text {WBGT }}$ & $\mathrm{RSW}_{\text {req }}$ & $\mathrm{RE}_{\text {req }}$ & $\mathrm{Rw}_{\text {req }}$ & $\mathrm{RSw}_{\mathrm{p}}$ & $\mathrm{RE}_{\mathrm{p}}$ & $\mathrm{Rw}_{\mathrm{p}}$ & $\mathrm{Rt}_{\mathrm{re}}$ \\
\hline G11 & 19 & 1.25 & 1.00 & 0.91 & 0.91 & 1.00 & 0.64 & 0.64 & 3.73 \\
\hline G12 & (60) & 1.08 & 1.00 & 0.80 & 0.80 & 1.00 & 0.76 & 0.76 & 0.57 \\
\hline G13* & 25 & 1.37 & 1.00 & 0.97 & 0.97 & 1.00 & 0.73 & 0.73 & 2.30 \\
\hline G14* & 14 & 1.68 & 1.00 & 1.12 & 1.12 & 1.00 & 0.64 & 0.64 & 5.88 \\
\hline G21 & 22 & 1.27 & 1.00 & 0.71 & 0.71 & 1.00 & 0.56 & 0.56 & 2.74 \\
\hline G22 & $(60)$ & 0.67 & 0.31 & 0.37 & 0.37 & 0.30 & 0.37 & 0.37 & 0.31 \\
\hline G23 & (60) & 1.17 & 1.00 & 0.80 & 0.80 & 1.00 & 0.75 & 0.75 & 0.77 \\
\hline G24 & (60) & 0.85 & 0.44 & 0.46 & 0.46 & 0.44 & 0.46 & 0.46 & 0.83 \\
\hline G31 & 36 & 1.15 & 1.00 & 1.14 & 1.14 & 1.00 & 0.88 & 0.88 & 1.63 \\
\hline G32 & (60) & 0.89 & 0.56 & 0.55 & 0.55 & 0.56 & 0.55 & 0.55 & 0.48 \\
\hline G33 & (60) & 1.06 & 1.00 & 0.82 & 0.82 & 1.00 & 0.80 & 0.80 & 0.47 \\
\hline G41 & (60) & 1.06 & 0.68 & 0.57 & 0.57 & 0.68 & 0.57 & 0.57 & 0.50 \\
\hline G42 & (60) & 1.13 & 0.49 & 0.55 & 0.55 & 0.49 & 0.55 & 0.55 & 0.33 \\
\hline G43 & (60) & 0.98 & 0.49 & 0.50 & 0.50 & 0.48 & 0.50 & 0.50 & 0.50 \\
\hline G44 & $(60)$ & 1.43 & 0.69 & 0.72 & 0.72 & 0.69 & 0.71 & 0.71 & 0.83 \\
\hline G51 & (60) & 1.14 & 0.64 & 0.56 & 0.56 & 0.63 & 0.56 & 0.56 & 0.50 \\
\hline G52 & (60) & 1.07 & 0.50 & 0.45 & 0.45 & 0.50 & 0.44 & 0.44 & 0.50 \\
\hline G53 & (60) & 1.27 & 0.46 & 0.51 & 0.51 & 0.46 & 0.50 & 0.50 & 0.33 \\
\hline G54 & (60) & 1.16 & 0.40 & 0.50 & 0.50 & 0.40 & 0.50 & 0.50 & 0.33 \\
\hline$r$ & - & Ref & 0.55 & 0.66 & 0.66 & - & - & - & - \\
\hline
\end{tabular}

*Out of the validity of the PHS model.

(60) More than $60 \mathrm{~min}$ to reach a rectal temperature of $38^{\circ} \mathrm{C}$.

temperature limit.

Figure 6 illustrates the rectal temperature $\left(t_{r e}\right)$ together with two other temperatures characteristic of thermal environments, namely the globe $\left(t_{g}\right)$ and the air $\left(t_{a}\right)$ temperatures. The dashed line is the maximum allowable rectal temperature $\left(t_{\text {re, } \max }=38^{\circ} \mathrm{C}\right)$ previously suggested by ${ }^{37)}$ and defined by ${ }^{3)}$.

The results show that the highest $t_{r e}$ values have a general trend to follow the highest values of both $t_{a}$ and $t_{g}$. The rectal temperature results varied between $37.3^{\circ} \mathrm{C}(\mathrm{G} 42$, $\mathrm{G} 53$ and G54) and $42.5^{\circ} \mathrm{C}$ (G14). Fourteen workplaces show $t_{r e}$ values lower or equal to $38^{\circ} \mathrm{C}$, which represents a desirable situation. Three workplaces present $t_{r e}$ values higher than maximum allowable $\left(t_{r e, \max }=38^{\circ} \mathrm{C}\right)$, but lower or equal to $40^{\circ} \mathrm{C}$, cases which deserve particular concerns. Beyond these, in two workplaces $t_{r e}$ is higher than $40^{\circ} \mathrm{C}$ (G11 and G14), a scenario that can be stated as critical, moreover because only one hour exposure is being considered. A very special attention is recommended to workplace G14 where the predicted $t_{r e}$ value is $42.5^{\circ} \mathrm{C}$, because this condition might even lead to a heat stroke episode, particularly if longer exposure shifts are admitted.

\section{Normalized parameters}

The normalized parameters defined in equation (1) together with the maximum allowable exposure time for the rectal temperature to reach $38^{\circ} \mathrm{C}\left(D_{\text {lim, tre }}\right)$, characterize both the potential severity of the environment and the thermal state of the worker. The ratios $\mathrm{R}_{\mathrm{WBGT}}, \mathrm{RSw}_{\text {req }}, \mathrm{RE}_{\text {req }}$ and $\mathrm{RW}_{\text {req }}$ and the value of $\mathrm{D}_{\text {lim,tre }}$ represent the potential severity of the environment and the ratios $\mathrm{RSw}_{\mathrm{p}}, \mathrm{Re}_{\mathrm{p}}$ and $\mathrm{Rw}_{\mathrm{p}}$ and $\mathrm{Rt}_{\mathrm{re}}$ represent the thermal state of the worker after an exposure of $60 \mathrm{~min}$. The outcomes of these relations obtained for the present sample are shown in Table 6. Moreover, Table 6 also shows a comparison between each of the ratios $\mathrm{RSW}_{\text {req }}, \mathrm{RE}_{\text {req }}$ and $\mathrm{RW}_{\text {req }}$ with the ratio $\mathrm{R}_{\mathrm{WBGT}}$. These comparisons are done using the Pearson product moment correlation coefficient $(r)$, here defined as

$$
\mathrm{r}=\frac{\sum_{\mathrm{i}=1}^{\mathrm{N}}\left[\left(\mathrm{R}_{2}-\overline{\mathrm{R}}_{2}\right)\left(\mathrm{R}_{1}-\overline{\mathrm{R}}_{1}\right)\right]}{\sqrt{\sum_{\mathrm{i}=1}^{\mathrm{N}}\left[\left(\mathrm{R}_{2}-\overline{\mathrm{R}}_{2}\right)^{2}\right] \sum_{\mathrm{i}=1}^{\mathrm{N}}\left[\left(\mathrm{R}_{1}-\overline{\mathrm{R}}_{1}\right)^{2}\right]}},
$$

where subscript 2 represents the values of the PHS parameters and subscript 1 refers to the WBGT index. 


\section{Discussion}

In this work the WBGT index and the PHS model were used to assess thermal environments within five Portuguese glass industries. These methods are two of the most well-known whenever an assessment of hot thermal environments is foreseen. There is much more practice regarding the WBGT due to its apparent simplicity. Otherwise, the PHS is being more often used to describe heat stress conditions since it was adopted by ISO as an assessment method. Despite some criticisms, the PHS enables a detailed analysis of a workplace and produces a significant amount of human body parameters, a fact that should encourage its use.

As aforementioned different working periods were assessed in the field, but by considering all the input data under the same assumption of one hour exposure, a more comprehensive comparison between different working conditions can be expected. However, it should be emphasized that the exposure period is a critical condition. Therefore, whenever more detailed analysis of a specific workplace is foreseen, then the gap between simulations and reality can be shortened by considering the actual exposure period.

The analysis of the evaporative heat rates show that a special attention is recommended whenever $E_{\text {req }}$ is higher than the corresponding $E_{\max }$. In the present sample this very critical situation is seen to happen two times (G14 and G31). When $E_{p}$ is lower than $E_{r e q}$, then the situation is critical and for long and continuous exposures there is a possibility of the body to reach the limits of normal thermoregulation and this clearly happens in five cases (G11, $\mathrm{G} 13, \mathrm{G} 14, \mathrm{G} 21, \mathrm{G} 31)$. When $E_{p}$ is equal to $E_{r e q}$ a normal thermoregulation is present. This clearly happens in eleven workplaces (G22, G24, G32, G41, G42, G43, G44, G51, G52, G53, G54).

In the present sample a special reference is due to workplace G14 the one that shows the highest rectal temperature and already classified as very critical for an hour of exposure. In this case a simulation for a continuous exposure period of $8 \mathrm{~h}$ was carried out and, as should be expected, if an exposure that long occurred, it would certainly lead to a dramatic end as evidenced by an unrealistic rectal temperature of $64^{\circ} \mathrm{C}$. Otherwise, the sweat rate results show that the maximum, the required and the predicted values are equal, another alert about the severe conditions and of the difficulty of the thermoregulatory system to cope with such challenge.

In terms of the assessment of the potential of the envi- ronment for heat stress, represented by $\mathrm{R}_{\mathrm{WBGT}}$, $\mathrm{RSw}_{\text {req, }}$, $\mathrm{RE}_{\text {req }}$ and $\mathrm{RW}_{\text {req }}$, the results shown in Table 6 put in evidence that each workplace is unique, then a global analysis of the workplaces is not representative of the working conditions in this activity sector.

As expected the results of Table 6 show that $\mathrm{RE}_{\text {req }}=\mathrm{RW}_{\text {req }}$. These ratios are different only when $\mathrm{RE}_{\text {req }}>1.70$ (maximum value imposed by the PHS model). Since this never happened in the present analysis one of these normalized parameters may be withdrawn.

The relation between the WBGT ratio ( $\mathrm{R}_{\mathrm{WBGT}}$ ) and the PHS environmental parameters is very poor with $\mathrm{RSw}_{\text {req }}$ (with a Pearson correlation coefficient $\mathrm{r}=0.55$ ) and weak with $\mathrm{RE}_{\text {req }}$ and $\mathrm{Rw}_{\text {req }}(\mathrm{r}=0.66)$. The ratio $\mathrm{R}_{\mathrm{WBGT}}$ always classifies the workplaces as more prone to heat stress than the PHS parameters. If the WBGT value of a given workplace is lower than its reference value $\left(\mathrm{R}_{\mathrm{WBGT}}<1.0\right)$ the PHS parameters exhibit also a value lower than their limits. However, in various cases $\mathrm{R}_{\mathrm{WBGT}}>1.0$ and the PHS ratios show values lower than 1.0 , namely in the case of industrial unit 5 where the $\mathrm{R}_{\mathrm{WBGT}}$ suggests workplaces as very critical while the PHS ratios indicate acceptable conditions. Such differences between the results of the WBGT index and of the PHS model are not so surprising, since the approach from the simplest to the most complex and the formulation of both methods are quite different. Therefore, it should be clear that a direct comparison between WBGT and PHS must be considered with great care.

Analysing the present sample in terms of the potential of the environment for heat stress, two workplaces can generally be categorized favourable (G22, G24), eight as acceptable (G32, G41, G42, G43, G51, G52, G53, G53), five as critical (G12, G21, G23, G33, G44) and four as very critical (G11, G13, G14, G31). This scenario, along with the experience of the authors in this kind of studies, allows the statement that this activity sector is among the most problematic when heat stress is concerned. Moreover, the situations stated in the present paper are similar to those reported by several authors ${ }^{23-27,41,42)}$ and it can be argued that the reality of the Portuguese glass industry is comparable to glass factories in several other countries.

In terms of the worker heat stress for an exposure of 60 min, represented by $\mathrm{RSw}_{\mathrm{p}}, \mathrm{RE}_{\mathrm{p}}, \mathrm{Rw}_{\mathrm{p}}$ and $\mathrm{Rt}_{\mathrm{re}}$, the results shown in Table 6 highlight that the worker heat stress level is related with the heat stress potential of the workplace. The workplaces identified as critical or very critical also lead to critical or very critical workers' heat stress. Similarly as for $\mathrm{RE}_{\text {req }}$ and $\mathrm{RW}_{\mathrm{req}}$, also $\mathrm{RE}_{\mathrm{p}}=\mathrm{Rw}_{\mathrm{p}}$. So, accordingly, one of these normalized parameters may be with- 
drawn.

Analysing the present sample in terms of worker heat stress, ten workplaces can generally be categorized favourable (G22, G32, G33, G41, G42, G43, G51, G52, G53 G54), four as acceptable (G12, G23, G24, G44), one as critical (G31) and four as very critical (G11, G13, G14, G21).

It is important to underline that the data gathered in this study showed that in two workplaces (G13 and G14) the air temperature is higher than the limit of applicability of the PHS model. This fact once more enhances the severity of the working conditions in this activity sector. In fact, more field data and experimental work is necessary to increase the actual data base in order to increase the knowledge about adverse working conditions. In very recent attempts with that goal in mind, the authors have been facing a strong opposition raised by CEO's of this sector. This is a matter of great apprehension that deserves further attention from Portuguese authorities. This setback was also felt in other studies ${ }^{30,31)}$. As already emphasized by ${ }^{41)}$ there is still a lot of work to do in order to achieve a more complete and reliable characterization of working environments in the heat, objective also shared by the research activities of the authors and by the ongoing European Project "Heat Shield".

\section{Conclusion}

In this work Portuguese glass industries were assessed. All the measurements took place in the industrial units and so the values of the physical parameters do correspond to real working conditions. The results of this field report sustain that the working conditions in the glass industry are equivalent worldwide. In fact, the glass industry is certainly one of the most difficult in occupational terms due to its intrinsic characteristics that do require the human presence and also due to the manufacturing procedures of the raw-material. The present study started in 1994 and since then several improvements in management and labour organization took place. Nevertheless there are still many reasons to give further attention to this activity sector, as the present contribution puts in evidence. Today, there is a more generalized concern about working conditions, but particularly in the more traditional glass industries the same concerns remain.

Fifteen out of nineteen workplaces show, according to the WBGT index, heat stress conditions; five workplaces show rectal temperatures higher than $38^{\circ} \mathrm{C}$; eight workplaces present equal required and maximum sweat rates; two workplaces show required evaporative heat flows higher than its maximum values and skin wittedness values higher than one. The results of this study also show that the workplaces heat stress potential and the workers' trend to develop a heat stress condition are related. Furthermore, the present sample shows working conditions that can be classified as favourable, acceptable, critical and very critical. On this basis, each workplace of the glass industry should be considered individually and a global analysis of the workplaces of this activity sector is not recommended.

The relation between the WBGT index and the PHS environmental parameters $\left(S w_{\text {req }}, E_{\text {req }}\right.$ and $\left.w_{\text {req }}\right)$ is not as strong as desired. This fact is not surprising since the approaches of both methods in dealing with heat stress are different. Therefore, the authors recommend the use of the WBGT index only at a screening level, while the use of the PHS model is recommended whenever possible and always when detailed assessments of working conditions are foreseen.

\section{References}

1) Epstein Y, Moran DS (2006) Thermal comfort and the heat stress indices. Ind Health 44, 388-98. [Medline] [CrossRef]

2) ISO 7243 (1989) Hot Environments - Estimation of the heat stress on working man, based on the WBGT index (Wet bulb globe temperature). ISO, Geneva.

3) ISO 7933 (2004a) Ergonomics of the thermal environment - Analytical determination and interpretation of heat stress using calculation of the predicted heat strain. ISO, Geneva.

4) ISO 15265 (2004b) Ergonomics of the thermal environment - Strategy of evaluation of the risk for the prevention of constraints or discomfort under thermal working conditions. ISO, Geneva.

5) Parsons K (2006) Heat stress standard ISO 7243 and its global application. Ind Health 44, 368-79. [Medline] [CrossRef]

6) Parsons K (2003) Human Thermal Environments - The effects of hot, moderate and cold environments on human health, comfort and performance. Second Edition, Taylor and Francis, London.

7) d'Ambrosio Alfano FR, Malchaire J, Palella BI, Riccio G (2014) WBGT index revisited after 60 years of use. Ann Occup Hyg 58, 955-70. [Medline] [CrossRef]

8) Quintela DA, Oliveira AVM, Cardoso D, Gaspar AR, Raimundo AM (2014) Assessment of the performance of globe thermometers under different environmental conditions. Occupational Safety and Hygiene II, Taylor \& Francis: London, eds: Arezes PM, Baptista JS, Barroso MP, Carneiro P, Cordeiro P, Costa N, Melo RB, Miguel AS, Perestrelo G, 523-8. [CrossRef]

9) Oliveira AVM, Gaspar AR, Raimundo AM, Quintela DA 
(2015b) On the Measurement of Globe Temperatures: Analysis of the Influence of Different Parameters. Extreme Physiology \& Medicine 4(Sup 1), A14 (selected abstract from the ICEE 2015 - 16th International Conference on Environmental Ergonomics, Portsmouth, England, 28 June-3 July. [CrossRef]

10) Oliveira AVM, Gaspar AR, Raimundo AM, Quintela DA (2015a) Assessment of thermal environments: Working conditions in the Portuguese ceramic industry in 1994 and 2012. Work 51, 457-70. [Medline] [CrossRef]

11) Budd GM (2008) Wet-bulb globe temperature (WBGT) its history and its limitations. J Sci Med Sport 11, 20-32. [Medline] [CrossRef]

12) d'Ambrosio Alfano FR, Palella BI, Riccio G (2012) On the problems related to natural wet bulb temperature indirect evaluation for the assessment of hot thermal environments by means of WBGT. Ann Occup Hyg 56, 1063-79. [Medline] [CrossRef]

13) ISO 7933 (1989) Hot environments - Analytical determination and interpretation of thermal stress using calculation of required sweat rate. ISO, Geneva.

14) Malchaire J, Piette A, Kampmann B, Mehnert P, Gebhardt H, Havenith G, Den Hartog E, Holmér I, Parsons K, Alfano G, Griefahn B (2001) Development and validation of the predicted heat strain model. Ann Occup Hyg 45, 123-35. [Medline] [CrossRef]

15) Malchaire JB (2006) Occupational heat stress assessment by the Predicted Heat Strain model. Ind Health 44, 380-7. [Medline] [CrossRef]

16) Rodrigues J, Oliveira AVM, Gaspar AR, Raimundo AM, Quintela DA (2016) Working conditions in the ceramic industry: assessment of the heat exposure with the Predicted Heat Strain (PHS) index. Occupational Safety and Hygiene IV, Taylor \& Francis: London, eds: Arezes PM, Baptista JS, Barroso MP, Carneiro P, Cordeiro P, Costa N, Melo RB, Miguel AS, Perestrelo G, 249-54. [CrossRef]

17) Wang F, Kuklane K, Gao C, Holmér I (2011) Can the PHS model (ISO7933) predict reasonable thermophysiological responses while wearing protective clothing in hot environments? Physiol Meas 32, 239-49. [Medline] [CrossRef]

18) Mehnert P, Peter Bröde P, Griefahn B (2002) Gender-related difference in sweat loss and its impact on exposure limits to heat stress. Int J Ind Ergon 29, 343-51. [CrossRef]

19) Malchaire J, Kampmann B, Mehnert P, Gebhardt H, Piette A, Havenith G, Holmér I, Parsons K, Alfano G, Griefahn B (2002) Assessment of the risk of heat disorders encountered during work in hot conditions. Int Arch Occup Environ Health 75, 153-62. [Medline] [CrossRef]

20) d'Ambrosio Alfano FR, Palella BI, Riccio G, Malchaire J (2016) On the effect of thermophysical properties of clothing on the heat strain predicted by PHS Model. Ann Occup Hyg 60, 231-51. [Medline] [CrossRef]

21) Malchaire J, Gebhardt HJ, Piette A (1999) Strategy for evaluation and prevention of risk due to work in thermal envi- ronments. Ann Occup Hyg 43, 367-76. [Medline] [CrossRef]

22) Malchaire J, Piette A (2006) The SOBANE strategy for the management of risk, as applied to whole-body or hand-arm vibration. Ann Occup Hyg 50, 411 -6. [Medline]

23) Abeysekera JDAG (1981) Thermal environment and subjective discomfort of glass-factory workers in Sri Lanka. J Hum Ergol (Tokyo) 10, 185-92. [Medline]

24) Bhanarkar AD, Srivastava A, Joseph AE, Kumar R (2005) Air pollution and heat exposure study in the workplace in a glass manufacturing unit in India. Environ Monit Assess 109, 73-80. [Medline] [CrossRef]

25) Pourmahabadian M, Adelkhah M, Azam K (2008) Heat exposure assessment in the working environment of a glass manufacturing unit. Iran J Environ Health Sci Eng 5, $141-$ 7.

26) Hoorfarasat G, Jafari MJ, Omidi L, Salehpour S, Khodakarim S, Haydarnezhad N (2015) Correlation between heat strain score index and WBGT index with physiological parameters in a glass manufacturing plant. Int J Occup Hyg 7, 202-8.

27) Beheshti MH, Nejad EB, Bahalgerdy B, Mehrafshan F, Arimy AZ (2015) Performance loss among workers due to heat stress in high-temperature workplaces. JOHE Spring 4, 116-24. [CrossRef]

28) Habibi Mohraz M, Ghahri A, Karimi M, Golbabaei F (2016) The Past and Future Trends of Heat Stress Based On Wet Bulb Globe Temperature Index in Outdoor Environment of Tehran City, Iran. Iran J Public Health 45, 787-94. [Medline]

29) Suzuki-Parker A, Kusaka H (2016) Future projections of labor hours based on WBGT for Tokyo and Osaka, Japan, using multi-period ensemble dynamical downscale simulations. Int J Biometeorol 60, 307-10. [Medline] [CrossRef]

30) Palella B, Quaranta F, Riccio G (2016) On the management and prevention of heat stress for crews onboard ships. Ocean Eng 112, 277-86. [CrossRef]

31) Orosa J, Oliveira A (2010) Assessment of work-related risk criteria onboard a ship as an aid to designing its onboard environment. J Mar Sci Technol 15, 16-22. [CrossRef]

32) Yaglou CP, Minard D (1957) Control of heat casualties at military training centers. AMA Arch Ind Health 16, $302-$ 16. [Medline]

33) NIOSH (1972) Occupational exposure to hot environment. National Institute for Occupational Safety and Health, HSM 72-10269, Department Health, Education and Welfare, USA.

34) ISO 7726 (1998) Ergonomics of the thermal environmentInstruments for measuring physical quantities. ISO, Geneva.

35) ISO 9920 (2007) Ergonomics of the thermal environmentEstimation of the thermal insulation and water vapour resistance of a clothing ensemble. ISO, Geneva.

36) ISO 8996 (1990) Ergonomics - Determination of the metabolic heat production. ISO, Geneva.

37) ISO 8996 (2004) Ergonomics of the thermal environment- 
Determination of metabolic rate. ISO, Geneva.

38) Barroso MP, Arezes PM, Costa LG, Miguel AS (2005) Anthropometric study of Portuguese workers. Int J Ind Ergon 35, 401-10. [CrossRef]

39) Saltin B, Hermansen L (1966) Esophageal, rectal, and muscle temperature during exercise. J Appl Physiol 21, $1757-$ 62. [Medline]

40) WHO (1969) Health Factors involved in Working under
Conditions of Heat Stress. World Health Organization, Technical Report Series 412, Geneva.

41) Xiang J, Bi P, Pisaniello D, Hansen A (2014) Health impacts of workplace heat exposure: an epidemiological review. Ind Health 52, 91-101. [Medline] [CrossRef]

42) Jay O, Kenny GP (2010) Heat exposure in the Canadian workplace. Am J Ind Med 53, 842-53. [Medline] [CrossRef] 